\section{Public Administration Research in Mainland China}

Min-Hyu Kim ${ }^{1,2}$, Huafang $\mathrm{Li}^{3}$, Marc Holzer ${ }^{4}$ and Mengzhong Zhang ${ }^{5}$

${ }^{1}$ Arizona State University, Phoenix, AZ, USA

${ }^{2}$ Hainan University, Haikou, China

${ }^{3}$ Grand Valley State University, Grand Rapids, MI, USA

${ }^{4}$ Suffolk University, Boston, MA, USA

${ }^{5}$ Gannon University, Erie, PA, USA

\section{Synonyms}

Chinese Public Administration

\section{Definition}

Public administration research in mainland China refers to studies on Chinese public sector, such as using Chinese government data to conduct research on organizational theories, human resource management, public budgeting, intersector administration, intergovernmental administration, intellectual history of public administration, as well as many subfields of studies within the domain of public administration and even nonprofit organizations.

\section{Introduction}

Public administration research in mainland China refers to the studies on Chinese public sector and even nonprofit organizations. As China is one of the world's fastest growing economies, many other countries are increasingly interested in the Chinese public administration system which, since the reforms of 1978 , has facilitated economic and social development. Academics and practitioners are drawn to the study of Chinese public administration because of the global influence of the Chinese market. The ancient and the contemporary wisdom of Chinese public administration can be valuable to public administration worldwide, both theoretically and practically (Holzer and Zhang 2002, 2009).

Largely missing from this important area of scholarly inquiry is empirical work that considers the patterns evident in the literature. Although several systematic reviews have examined Chinese public administration literature, none have conducted a word cloud and cluster analysis based on content analysis of the words in the abstracts. Accordingly, we performed a systematic content analysis of words used in the studies' abstracts to obtain a more objective sense of their substantive content, so that other researchers might learn useful lessons from a semantic analysis of the abstracts in studies of Chinese public administration.

This entry begins with a brief discussion of the development of Chinese public administration as 
an academic discipline, which is the historical root of such public administration research. Next, the topic of comparative studies of public administration is introduced, followed by a review of Chinese public administration research. This entry then provides the results of a systematic and objective content analysis of words in the studies' abstracts and lastly examines the potential for conducting research on Chinese public administration as a comparative approach to understand public administration in the global context.

\section{The Development of Chinese Public Administration as an Academic Discipline}

The intellectual roots of public administration in China can be traced back at least perhaps thousand years, although public administration as an academic discipline is a comparatively recent phenomenon (Holzer and Zhang 2002). After Qin Shi Huang united China in $221 \mathrm{BC}$, successive dynasties established the first centralized Chinese bureaucratic system, one which enabled the emperor of China to control such a large territory. The essence of this civil service system was to recruit the "best and brightest" into the government according to their merits, demonstrated by their test scores rather than their blood linkage. The imperial examination system (ancient Chinese civil service system) in China continued for 1300 years (Roberts 1993). In the late nineteenth century, Kang Youwei imported the concepts and theories of contemporary public administration from Japan, where public administration was taught by German scholars (Harris 2002).

The origins of public administration as an academic discipline in China can be traced back to 1905, when it was first taught as a subfield of political science in the School of Law and Politics in Guangdong province (Wang 2006). However, in the early 1950s, Mao Zedong's administration believed public administration, as well as other social science disciplines, was irrelevant to the socialist model because the administration considered resolution of class struggles to be the
Communist Party's main task. Thus, together with other disciplines, public administration as a field of study essentially disappeared in China for the three decades between 1952 and 1982.

It was not until the 1980s that public administration as an academic discipline was reintroduced in China (Yu et al. 2012). In 1985, the government held a meeting to discuss the development of public administration in China. Soon after the meeting, the State Council approved the launch of the Chinese Public Administration Society. From the latter half of the 1980s, China's public administration development was rapid (Zhang 1993). In the early 1990s, there were more than a thousand public administration books covering a variety of subjects. Academic journals and research organizations began to flourish. Between 1984 and 1992, more than two million state cadres received public administration training via several channels (Zhang 1993).

In 1994, the Chinese National School of Administration (CNSA) was established. In 2010, CNSA was changed to its present name, "Chinese Academy of Governance." Many stateowned provincial- and city-level public administration schools were established thereafter.

In 2002, public and nonprofit employees entered the first group of 24 MPA programs in the People's Republic of China (PRC), and by 2015 the Chinese government had authorized 228 universities to offer MPA programs (National MPA Education Steering Committee 2015). In comparison, according to NASPAA (2018), there were 190 MPA-related programs accredited in the United States and perhaps as many more offered the MPA without NASPAA accreditation (but in colleges and universities accredited by regional higher education associations, as are virtually all higher education entities in the United States). The United States started its first MPA program in 1924 at Syracuse University's Maxwell School, almost a century ago. In contrast, within little more than 15 years, the PRC has now developed 228 MPA programs, reflecting an urgent demand for talented public employees to deal with increasingly complicated governance issues in a rapidly transitioning society. 


\section{Comparative Studies of Public Administration}

Comparative public administration is defined as the quest for patterns and regularities in administrative action and behavior (Riggs 1961). The field focuses largely on reform and capacity building and often seeks to identify universal patterns in organizational structures and processes that promote the most desirable policy outcomes. Governments differ greatly in their historical, social, and economic characteristics and exhibit a range of administrative arrangements. The variation in these administrative systems is due to a variety of factors, including social, cultural, political, and technological factors. Comparative public administration focuses primarily on national (and less so on subnational) administrative systems in the global contexts. It also explores the way in which the organizational structures and processes facilitate or inhibit policy implementation.

The field of public administration emphasizes the need for comparative studies to test the effectiveness of public administration theories (Fritzen 2010). However, to date, few efforts have been undertaken with respect to China. Most of the previous literature consists of comparisons of the public administration experience in different democracies (e.g., see Grimmelikhuijsen et al. 2013; Kim et al. 2013). Compared to the United States and Europe, less scholarly attention is given to authoritarian systems such as the PRC. Riggs (1961) criticized the failure of Americanized and Europeanized administrative theories to apply to different contexts and argued that it should be rectified through comparative administration research.

Comparative public administration is an inevitable dimension of research, given that globalization has transformed the roles of government (Holzer and Kasymova 2012). Globalization has changed the role of government from a welfare state to "hollow state" (Frederickson 2006), "contracting state" (Farazmand 1999; Smith and Lipsky 2009), or "corporate administrative state" (Farazmand 1997a, b, 1999). In that sense, Jreisat (2005) argues that both the national and international environments need to be considered when studying a particular administrative reform.

Kettl (2000) argues that comparative public administration is compelling, as the US government has become increasingly involved in world governance. In a similar vein, Riggs (1961) suggests that the processes of generating reliable knowledge and developing the principles of public administration are inherently comparative. Riggs (1961) also documents that scholars can no longer afford to base their theories on the "exceptional American experience" because it limits comparative public administration to the study of foreign governments. Heady (2001) demonstrates that the comparative method is essential to developing administrative theory and improving its application. Collier (1993) notes that comparison is central to a satisfactory analysis to the extent that the scientific method is unavoidably comparative. Studies in other fields show that most social scientists consider the comparative approach to be the methodological core of the humanistic and scientific method (Almond and Verba 2015). Aberbach and Rockman (1987) echo such sentiments, indicating that comparative study advances scholarship to the level of conceptual and methodological self-consciousness. Offering more nuance to this argument, Aberbach and Rockman (1987) note that it is very difficult to achieve a clear understanding with non-comparative studies of public administration. Further, comparative public administration is a concern because of its broader social and political consequences; specifically, it helps practitioners to better understand their own institutions, the changing demographics of their communities, and "the different political contexts" they face (Khademian 1998, p. 273).

\section{Reviews of Chinese Public Administration Studies}

Guided by the literature cited above, in recent years, discussions of Chinese public administration that use a comparative perspective have emerged (Gao 2013; Mingus and Jing 2016; Walker et al. 2014; Wu et al. 2013). For example, in the first issue of Chinese Public Administration 
Review, Holzer and Zhang (2002) emphasized "...the necessity of Chinese scholars to learn from international scholars in the field of public administration." In a similar vein, scholars and practitioners in the United States can learn about the challenges of effective public management and the reform of public organizations through comparative studies between the United States and China. Although previous studies examine recent trends in Chinese public administration research, no study has, as yet, conducted a systematic content analysis of words in the studies' abstracts to provide a different and more objective sense of the substantive content. This study began with the belief that conceptualizing the studies of Chinese public administration through a content analysis of the abstracts could help practitioners develop strategic policies to prepare effectively for the challenges of globalization and an information-oriented society. In that vein, we have conducted a word-based analysis of the relevant literature to illustrate the ways in which academics and practitioners can avoid cultural biases in building theories and implementing policies by understanding the limitations and new possibilities presented in the literature on Chinese public administration.

Mingus and Jing (2016) review Chinese language literature to discuss the relevance of Behn (1995)'s questions on micromanagement, motivation, and measurement in the Chinese context. They propose alternate wording for Behn's questions to make them meaningful in the Chinese cultural and institutional context, but they avoid suggestions as to replacing the basic Chinese political structure. Walker et al. (2014) review the English language literature on public administration between 1999 and 2009 regarding East and Southeast Asia as identified in the Web of Science. The authors identify four major characteristics: first, its comparative nature; second, its focus on system and regime change, as well as policies, as the major topics and units of analysis; third, its literature review is based primarily on normative argumentation, and when it is an empirical study, it relies typically on secondary data; and, lastly it is largely interdisciplinary, and while it draws from many disciplines and scholars from all around the globe, it is dominated by scholars who work in English-speaking countries.

Gao (2013) reviews the public administration research literature published in Hong Kong and Macau between 1999 and 2009. Gao examines the ways in which public administration developed in the two city-states in the post-handover period and the ways in which those developments affected the study of public administration in the two jurisdictions. The findings reveal differences between the two cities. In general, studies of Hong Kong engage in testing and building theories using rigorous methodologies and adopting a comparative outlook and receive far better funding than studies conducted in Macau. The focus of studies in Macau differs from those in Hong Kong because the public administration community in Macau sought to foster closer interactions between academics and practitioners.

Wu et al. (2013) provide an overview of public administration research in China based on a sample of 2,877 articles published in the top 6 Chinese language journals in mainland China and Taiwan between 1998 and 2008. Their analysis of these publications suggests that scholars in Taiwan have made great strides in a short period to improve research quality and provide their colleagues across the Taiwan Strait with valuable insights into the future directions of the field.

Kim et al. (2018) systematically examined the existing studies on public management research in mainland China from 1996 to 2016. They carefully selected the previous research based on the PRISMA guidelines and systematically review the journal names, publication frequencies, authorships, research focus, topics, and methodologies. Their study can be evaluated as progress in that they carried out more in-depth analyses compared to the prior research.

While these studies provide insightful contributions to the literature and help us understand patterns in Chinese public administration research, two questions remain: "What are the most commonly used words in the abstracts of the previous literature on Chinese public administration?" and "How are these words related and tied together?" Our utilization of objective 
analysis using word cloud and cluster analysis in this study sharpens the validity of results.

\section{A Systematic Content Analysis of Words Used in the Abstracts}

This study conducted a systematic literature review according to the PRISMA guidelines (Moher et al. 2009). First, data were collected by searching various databases including Web of Science, Scopus, EconLit, and EBSCO Academic Search Premier. Within these, this study searched journal articles published from 1996 through 2016 to identify those that included "China" and "public administration" in their titles, topics, abstracts, or keywords $(n=4,403)$. Second, 1,462 manuscripts were selected after removing 2,941 duplicates. Third, this study evaluated the titles and abstracts and excluded 769 papers unrelated to Chinese public administration $(n=693)$. Lastly, we examined the full texts of those and excluded 347 articles because they were not relevant to public administration and thus not suitable for inclusion. These decision rules resulted in 346 articles for this study.

After looking at the journal articles' descriptive analyses, a systematic content analysis of words used in the abstracts was performed to obtain a different and more objective sense of the substantive content of the studies in the review. Figure 1 shows the resulting word cloud, which represents the frequency of words that appeared in the abstracts. Figure 2 provides the

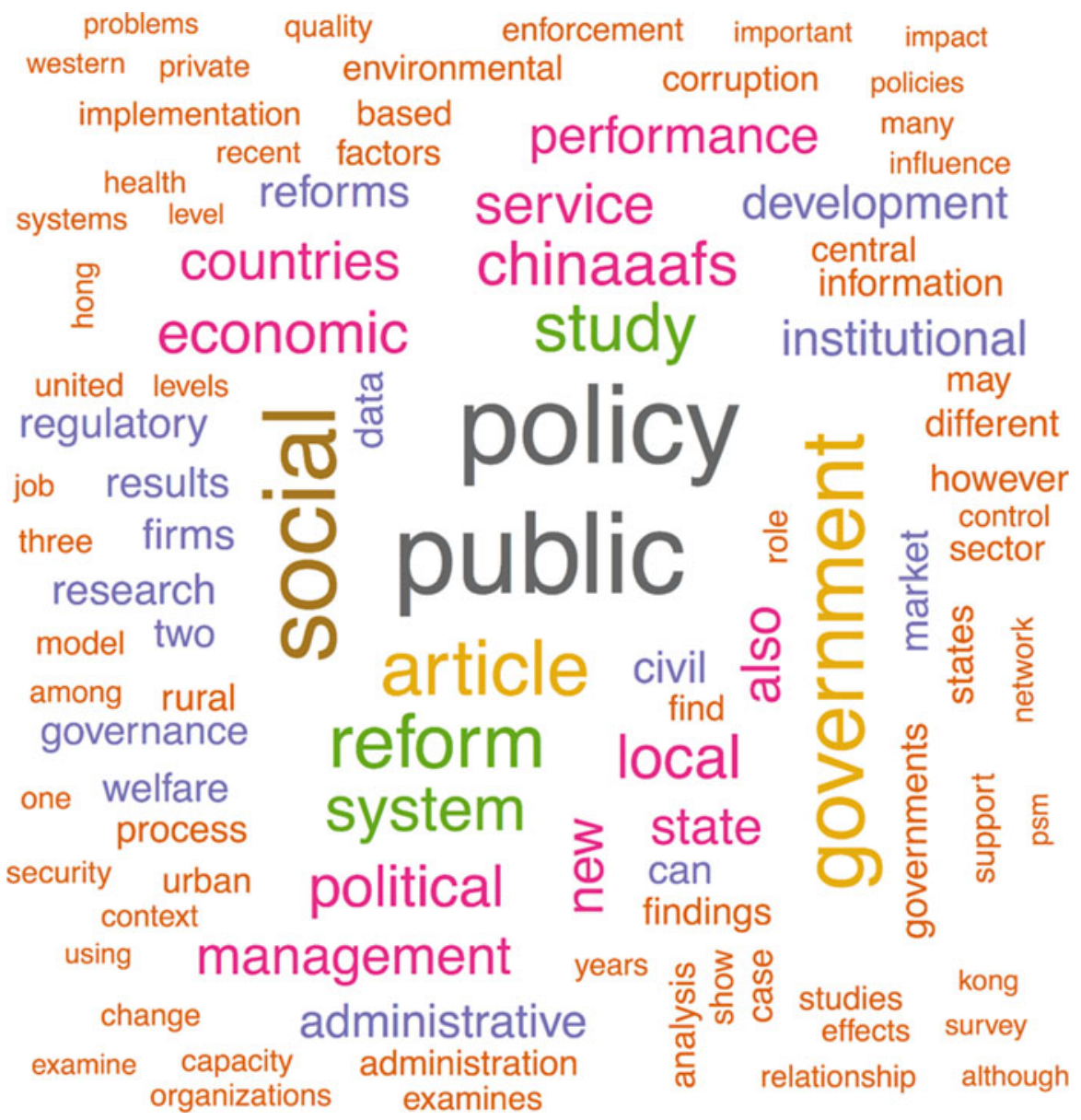

Public Administration Research in Mainland China, Fig. 1 Word cloud of abstracts 
Public Administration Research in Mainland China, Fig. 2 Clusters of words that appeared frequently in abstracts

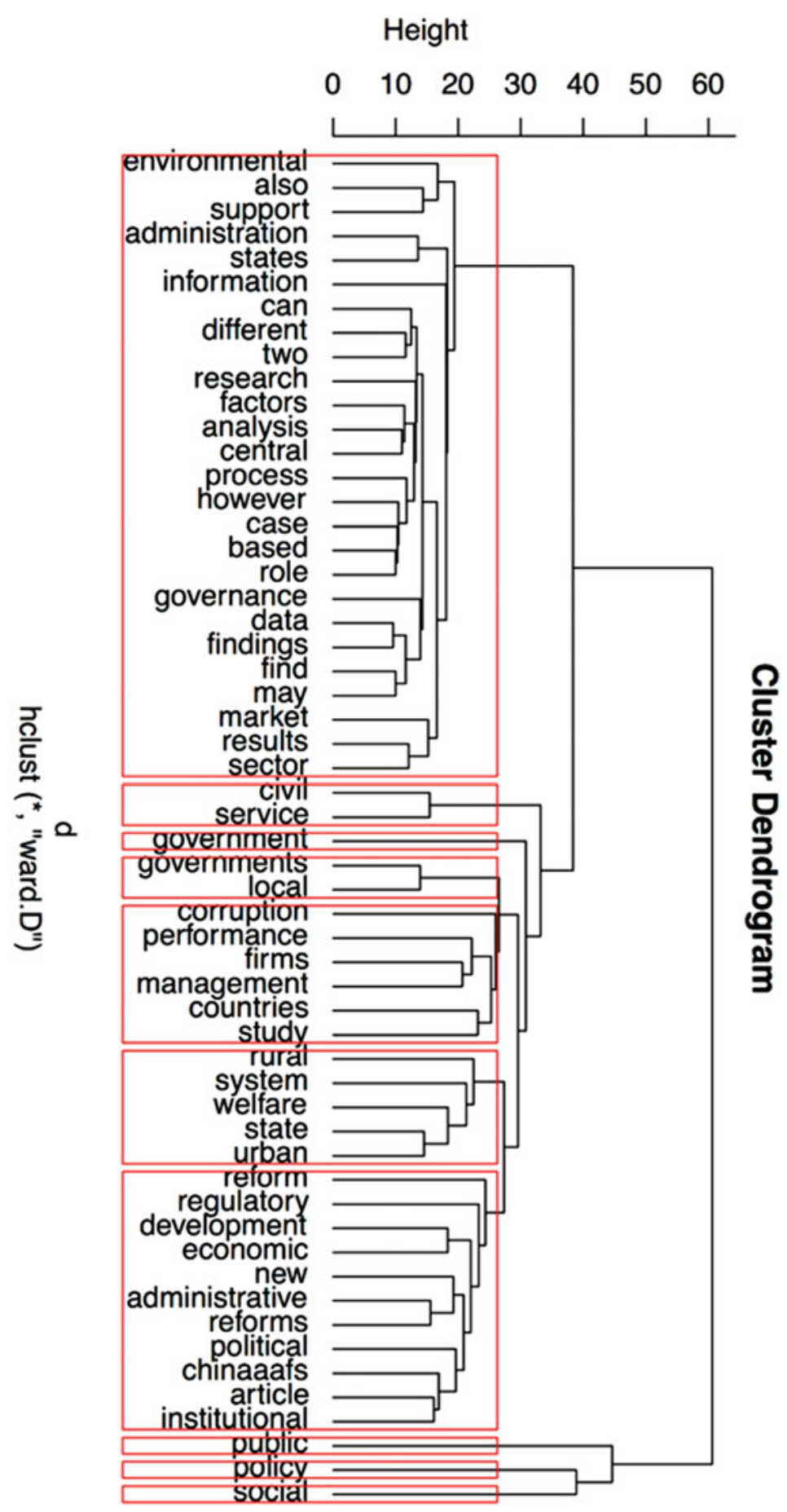

results of the cluster analysis, which shows which of these words tended to appear together in the abstracts. Both analyses focused on the words used most frequently.
A systematic and more objective content analysis of words in the studies' abstracts also was performed. The content analysis, which used word clouds and clusters to identify important 
topics, is based on $\mathrm{Li}$ and Van Ryzin (2017). Figures 1 and 2 show the word clouds and clusters of words, respectively, used frequently in these abstracts.

The word cloud in Fig. 1 shows the words used most frequently across abstracts to show that the larger the font sizes, the higher the frequencies. The word cloud excluded the main topic words of "China," "Chinese," and "administration." "Public" and "policy," then, were the words used most frequently because of their relevance to the theme. The word cloud also illustrates that most of the studies focused on "government," "social," "reform," "local," "political," "economic," "performance," and "management." The word cloud alone, however, did not provide precise information about linkages between words. Thus, Fig. 2 shows a related cluster analysis that presents the way in which these words were linked in the abstracts. The cluster analysis shows distinct local governments, institutional governance, performance management, economic development, and administrative reform clusters and a large and rather mixed cluster composed of a variety of other words that appeared in the abstracts. These results complement our previous categorization of policy fields and suggest that local governments, institutional governance, performance management, economic development, and administrative reform are some of the most common themes to date in studies of Chinese public administration.

\section{Conclusion}

This study was designed to fill the gap in the literature on Chinese public administration by reviewing English language publications in the top 25 journals in the field. A comparative perspective indicates that global leadership requires global understanding, which evolves from appropriate education that uses suitable methods and content (Jreisat 2005). Previous systematic reviews rely largely on descriptive analyses of the literature. This study, however, uses word cloud and cluster analyses based on content analyses of abstracts in 301 articles published between 1996 and 2016 to obtain a different and more objective sense of the substantive content of the studies in the review.

In summary, this research concluded that the study of Chinese public administration is still very much an ongoing effort. Despite some limitations, our study demonstrated that word cloud and cluster analyses, used rarely in previous reviews, are powerful tools for examining meanings extracted from texts by visualizing the words used in abstracts and interpreting various perspectives provided in the literature over time. Finally, future studies could examine whether performance management results in more efficient and better public services in China.

\section{Cross-References}

Case Studies of Public Administration in the People's Republic of China

- China's Public Administration Reform

- Chinese Government and Public Policies

- Chinese Public and Nonprofit Management

Development of Public Administration in China

\section{References}

Aberbach JD, Rockman BA (1987) Comparative administration methods, muddles, and models. Adm Soc 18(4):473-506

Almond GA, Verba S (2015) The civic culture: political attitudes and democracy in five nations. Princeton University Press, Princeton

Behn RD (1995) The big questions of public management. Public Adm Rev 55(4):313-324

Bradsher K, Rappeport A (2018) U.S.-China trade truce gives both sides political breathing room. Retrived 7 Jan 2019, from https://www.nytimes.com/2018/12/ 02/business/trade-truce-china-us.html

Collier D (1993) The comparative method. In: Finifter AW (ed) Political science: the state of discipline II. American Political Science Association, Washington, DC

Farazmand A (1997a) From civil to non-civil administration: the biggest challenge to the state and public administration. Paper presented at the national conference of the American society for public administration, Philadelphia, July

Farazmand A (1997b) Institutionalization of the new administrative state/role. Paper presented at the annual 
conference of the American Political Science Association (APSA), Washington, DC, August

Farazmand A (1999) Globalization and public administration. Public Adm Rev 59(6):509-522

Frederickson DG (2006) Measuring the performance of the hollow state. Georgetown University Press, Washington, DC

Fritzen SA (2010) Envisioning public administration as a scholarly field in 2020: toward global and comparative administrative theorizing. Public Adm Rev 70(s1):300-301

Gao J (2013) Public administration research in Hong Kong and Macau: a review of journal articles published from 1999 to 2009. Am Rev Public Adm 44(2):168-186

Grimmelikhuijsen S, Porumbescu G, Hong B, Im T (2013) The effect of transparency on trust in Government: A cross-national comparative experiment. Public Adm Rev 73(4):575-586. https://doi.org/10.1111/ puar.2013.73.issue-4

Harris P (2002) The origins of modern citizenship in China. Asia Pac Viewp 43(2):181-203

Heady F (2001) Public administration, a comparative perspective. CRC Press, Philadelphia

Holzer M, Kasymova J (2012) Restating the relevance of comparative public administration. Public Adm Rev 72(1):162-164

Holzer M, Zhang M (2002) Chinese public administration review: an introduction. Chin Publ Adm Rev 1(1):5-8

Holzer M, Zhang M (2009) Introduction to the special issue on comparative Chinese/American public administration. Public Adm Rev 69:S5-S12

Jreisat JE (2005) Comparative public administration is back in, prudently. Public Adm Rev 65(2):231-242

Kettl DF (2000) The transformation of governance: globalization, devolution, and the role of government. Public Adm Rev 60(6):488-497

Khademian AM (1998) What do we want public managersto be? Comparing Reforms. Public Adm Rev 58(3):269-273

Kim S, Vandenabeele W, Wright BE, Andersen LB, Cerase FP, Christensen RK, Liu B (2013) Investigating the structure and meaning of public service motivation across populations: Developing an international instrument and addressing issues of measurement invariance. Journal of Public Administration Research and Theory 23(1):79-102. https://doi.org/10.1093/jopart/mus027

Kim M, Li H, Holzer M, Zhang M (2018) Public Administration Research in Mainland China: a systematic review of Chinese Public Administration in English
Language Journals (1996-2016). Int J Public Adm 1-12. Advanced Online Publication. https://doi.org/ 10.1080/01900692.2018.1506936

Li H, Van Ryzin GG (2017) A systematic review of experimental studies in Public Management Journals. In: James O, Jilke S, Van Ryzin GG (eds) Experiments in public management research. Cambridge University Press, London, pp 20-36

Mingus MS, Jing Z (2016) The big questions of Chinese public management research. Adm Soc 49(6):775-797

Moher D, Liberati A, Tetzlaff J, Altman DG (2009) Preferred reporting items for systematic reviews and metaanalyses: the PRISMA statement. PLoS Med 6(7): e1000097

NASPAA (2018) NASPAA annual accreditation data report 2017-2018. Available from https://accreditation.naspaa. org/resources/roster-of-accredited-programs/. Accessed 20 Apr 2018

National MPA Education Steering Committee (2015) Explanation to several issues about the guidelines of educational plans for MPA degree program. Retrieved July 19, 2018, from www.mpa.org.cn/displaynews1. asp?id=76

Riggs FW (1961) Ecology of public administration. Asia Publishing House, Cambridge, MA

Roberts JM (1993) A short history of the world. Oxford University Press, London

Smith SR, Lipsky M (2009) Nonprofits for hire: the welfare state in the age of contracting. Harvard University Press, Cambridge, MA

Walker RM, Brewer GA, Choi Y (2014) Public administration research in east and Southeast Asia a review of the English language evidence, 1999-2009. Am Rev Public Adm 44(2):131-150

Wang L (2006) A probe into China's public administration education and the construction of the subject of public administration. Chin Publ Adm Rev 1(1):31-36

Wilson W (1887) The study of administration. Polit Sci Q 2(2):197-222

Wu X, He YL, Sun MTW (2013) Public administration research in mainland China and Taiwan: an assessment of journal publications, 1998-2008. Public Adm 91(2):261-280

Yu W, Rubin M, Wu W (2012) An executive MPA program for China: lessons from the field. J Publ Aff Educ 18(3):545-564

Zhang CF (1993) Public administration in China. In: Mills M, Nagel S (eds) Public administration in China. Greenwood Press, Westport, p 3 